v. 01, n. 02 : pp. $105-117,2005$

ISSN $1808-0448$

D.O.I.: $10.3895 / \mathrm{S} 1808-04482005000200009$
Revista Gestão Industrial

\title{
VALORAÇÃO ECONÔMICA DO MEIO AMBIENTE DENTRO DO CONTEXTO DO DESENVOLVIMENTO SUSTENTÁVEL
}

\section{ECONOMICAL VALUATION OF THE ENVIRONMENT INSIDE OF THE CONTEXT OF THE SUSTAINABLE DEVELOPMENT}

\author{
Katty Maria da Costa Mattos ${ }^{1}$; Karen Maria da Costa Mattos ${ }^{2}$; Arthur Mattos $^{3}$ \\ ${ }^{1}$ Doutora em Ciências da Engenharia Ambiental - EESC - USP - São Carlos - SP, \\ ktmattos@terra.com.br \\ ${ }^{2}$ Doutora- UFRN - Natal - RN - Brasil karenmattos@yahoo.com.br \\ ${ }^{3}$ Professor Doutor - livre-docente - UFRN - Natal - RN, armattos@ct.ufrn.br \\ Recebido para publicação em: 13/01/2005 \\ Aceito para publicação em: 02/06/2005
}

\begin{abstract}
RESUMO
O desenvolvimento econômico e social e a gestão ambiental estão indissoluvelmente vinculados $e$ devem ser tratados mediante a mudança do conteúdo, das modalidades e das utilizações do crescimento. A preocupação com os problemas ambientais aparece como um elemento importante a respeito do crescimento material e econômico e da qualidade de vida. O meio ambiente é considerado uma dimensão do desenvolvimento e deve então ser internalizado em todos os níveis de decisão. A análise econômica neoclássica, modelo dominante a respeito das questões microeconômicas, se esforça para confiar ao mercado a resolução dos problemas ambientais. Uma das maiores limitações dessa teoria é que os sistemas econômicos dão valor aos bens e serviços produzidos pelo Homem e não valoram os bens e serviços produzidos pela Natureza. Assim, os valores dados aos produtos e serviços não correspondem aos seus valores reais. Como a operacionalização da sustentabilidade - compreendida como a capacidade das gerações presentes alcançarem suas necessidades sem comprometer a capacidade das gerações futuras também fazêelo - é o grande desafio civilizatório das próximas décadas, faz-se necessário buscar instrumentos da gestão ambiental que garantam um desenvolvimento realmente sustentável.
\end{abstract}

Palavras-Chave: Desenvolvimento Sustentável, Valoração Econômica, Meio Ambiente.

\section{Introdução}

A consciência dos problemas ambientais aparece como um ponto importante a respeito do crescimento material e econômico e da qualidade de vida. A qualidade de vida para alguns é obtida às custas da limitação das produções materiais e para outros, ao contrário, ela é proporcional à abundância dos produtos.

A aposta em um desenvolvimento econômico e social contínuo, harmonizado com a gestão racional do ambiente, segundo SACHS (1986), passa pela redefinição de todos os objetivos e de 
todas as modalidades de ação. O ambiente é considerado uma dimensão do desenvolvimento e deve então ser internalizado em todos os níveis de decisão.

A economia atual do meio ambiente procura uma abordagem preventiva contra as catástrofes ambientais iminentes pregando a conservação da biodiversidade mediante uma ótica que considere as necessidades potenciais das gerações futuras. Isso pressupõe que os limites ao crescimento fundamentados na escassez dos recursos naturais e sua capacidade de suporte são reais e não necessariamente superáveis por meio do progresso tecnológico.

O desenvolvimento e o meio ambiente estão indissoluvelmente vinculados e devem ser tratados mediante a mudança do conteúdo, das modalidades e das utilizações do crescimento. Três critérios fundamentais devem ser obedecidos simultaneamente: eqüidade social, prudência ecológica e eficiência econômica. Este conceito normativo básico emergiu da Conferência de Estocolmo em 1972, designado à época como “abordagem do ecodesenvolvimento" e posteriormente renomeado "desenvolvimento sustentável” (SACHS, 1993).

A eficiência ou viabilidade econômica, segundo ROMEIRO (1991), “pressupõe a concepção de sistemas produtivos onde os custos de produção, medidos pela produtividade do trabalho obtida, sejam compatíveis com os níveis de bem estar social considerados como minimamente aceitáveis. A eqüidade social pressupõe a solidariedade sincrônica entre classes sociais, o que implica optar por padrões tecnológicos que propiciem uma distribuição mais equitativa da renda gerada".

A economia, uma disciplina marcada pela coexistência de vários paradigmas, pode ser classificada distinguindo-se as escolas neoclássica, keynesiana, institucionalista e marxista. Mas, segundo TOLMASQUIM (1995), no que diz respeito às questões microeconômicas, a teoria neoclássica se consolidou como modelo dominante. Sua base teórica aplicada aos problemas ambientais constitui uma especialidade, "economia do meio ambiente".

A teoria neoclássica centra sua análise sobre o problema da alocação ótima de recursos, sendo que o sistema de mercado determina um equilíbrio único e estável. A análise econômica neoclássica se esforça para confiar ao mercado a resolução dos problemas ambientais.

Uma das maiores limitações dessa teoria é que os sistemas econômicos dão valor aos bens e serviços produzidos pelo Homem e não valoram os bens e serviços produzidos pela Natureza. Assim, os valores dados aos produtos e serviços não correspondem aos seus valores reais.

Segundo MARQUES \& COMUNE (1996) existe a necessidade de valorar corretamente os bens e serviços do meio ambiente, entendidos no desempenho das funções: provisão de matériasprimas, capacidade de assimilação de resíduos, amenidade, estética e recreação, biodiversidade e capacidade de suporte às diversas formas de vida no planeta Terra. Há, também, necessidade de procurar integrar esses valores apropriadamente estimados, às decisões sobre a política econômica e ambiental e aos cálculos das contas econômicas nacionais. 
Atualmente, há uma emergente mudança de paradigmas em evolução na sociedade, onde é preciso perceber o conjunto de valores que direcionam nosso desenvolvimento econômico e nossa relação com o ambiente natural, que encontrou uma barreira intransponível que são os limites da biosfera.

Essa mudança paradigmática aparece como um elemento reorganizador dos processos econômicos, cujo principal eixo é a busca da sustentabilidade, compreendida como a capacidade das gerações presentes alcançarem suas necessidades, sem comprometer a capacidade das gerações futuras também fazê-lo. A operacionalização da sustentabilidade é o grande desafio civilizatório das próximas décadas.

\section{Evolução da economia do meio ambiente}

A economia como ciência tem desenvolvido, ao longo dos anos, diversas formas de análise relacionada ao ambiente natural. Esta análise pode ser dividida em três fases: Economia de Recursos Naturais, Economia Ambiental e Economia Ecológica.

\subsection{Economia de recursos naturais}

Difundida nas décadas de 60 e 70, tinha sua ênfase na forma de utilização dos recursos naturais. O objetivo era alcançar o uso ótimo de recursos renováveis e não-renováveis, porém não se conseguiu evitar a degradação ambiental. Assim, nesta fase correu-se o risco de levar os recursos naturais à completa exaustão ou extinção.

\subsection{Economia Ambiental}

Difundida na década de 80, tinha sua ênfase voltada à questão da poluição, que era percebida como uma externalidade do processo de produção e consumo que podia ser tratada pelos vários meios de internalização de custos ambientais nos preços dos produtos.

Tanto a Economia de Recursos Naturais quanto a Economia Ambiental, segundo MERICO (1996), mostraram-se insuficientes para produzir uma ampla introdução do ambiente natural na análise econômica, dado que não discutiam uma escala adequada das atividades econômicas em relação aos ecossistemas e em relação à própria biosfera.

\subsection{Economia Ecológica}


Uma nova abordagem que representa uma evolução das formas de análise anteriores, englobando a problemática do uso de recursos naturais e as externalidades do processo produtivo, com ênfase no uso sustentável das funções ambientais e na capacidade dos ecossistemas em geral de suportar a carga imposta pelo funcionamento da economia, considerando custos e benefícios da expansão da atividade humana.

Economia ecológica é, de acordo com COSTANZA (1994), uma nova abordagem transdisciplinar (que vai além das concepções tradicionais das disciplinas científicas, procurando integrar e sintetizar muitas perspectivas disciplinares diferentes) que contempla toda a gama de inter-relacionamento entre os sistemas econômico e ecológico.

Segundo BUARQUE (1994), a economia ecológica deverá incorporar todas as relações da vida como parte de seu estudo. Exigindo não apenas a incorporação da dimensão ecológica, como também a consideração do longo prazo. O espaço físico da economia deverá ir além dos limites das empresas e da nação, abrangendo toda a ecologia; o tempo das análises não poderá ficar restrito ao curto prazo, devendo incorporar todo o futuro no qual os efeitos das decisões econômicas se fazem sentir.

A economia ecológica, de acordo com MAY (1995), procura uma abordagem contra as catástrofes ambientais iminentes pregando a conservação dos recursos naturais mediante uma ótica que adequadamente considere as necessidades potenciais das gerações futuras.

Essa abordagem pressupõe que os limites ao crescimento fundamentados na escassez dos recursos naturais e sua capacidade de suporte são reais e não necessariamente superáveis por meio do progresso tecnológico. Isto significa que ao lado dos mecanismos tradicionais de alocação e distribuição geralmente aceitos na análise econômica, a economia ecológica acrescenta o conceito de escala, no que se refere ao volume físico de matéria e energia que é convertido e absorvido nos processos entrópicos da expansão econômica.

Existem duas vertentes metodológicas principais, de acordo com MAY (1996), que têm norteado a utilização da economia ecológica como instrumento no processo decisório, que são:

- Expandir as fronteiras da análise tradicional de custo-benefício, buscando uma quantificação das interações entre a atividade econômica e as funções ecológicas, utilizando métodos de valoração ambiental.

- Estabelecer limites à interferência da economia nos ecossistemas naturais, reconhecendo o extenso trabalho empírico que seria necessário para expandir as fronteiras da análise de custobenefício para incorporar a valoração ambiental de forma adequada, necessitando da participação da sociedade nas escolhas de políticas onde existam percepções diferenciadas de valores.

A economia ecológica almeja o desenvolvimento sustentável, sendo que uma definição do funcionamento do desenvolvimento sustentável, conforme PEARCE \& TURNER (1991), envolve a 
maximização dos benefícios líquidos do desenvolvimento econômico, sujeito a manter os serviços e qualidade dos recursos naturais ao longo do tempo.

O desenvolvimento econômico tem sido amplamente interpretado para não incluir só aumentos de renda per capita, mas também outros elementos de bem estar social. Este desenvolvimento envolverá necessariamente mudança estrutural dentro da economia e da sociedade. Mantendo os serviços e a qualidade da ação de recursos com o passar do tempo, implicando a aceitação das seguintes regras:

- Utilizar recursos renováveis com taxas menores ou iguais à taxa natural de regeneração.

- Otimizar a eficiência dos recursos não renováveis utilizados, sujeito a substituição desses recursos por novas tecnologias.

Segundo COMMON (1995), as características essenciais do desenvolvimento sustentável para a sociedade necessita de três imperativos ecológicos:

1. O tamanho da população na Terra deve ser relativamente estável (ou decrescente).

2. A população global e suas atividades não devem ultrapassar os limites dos recursos naturais impostos pela biosfera.

3. A organização da sociedade e o sistema econômico devem ser tais que a saúde humana e a qualidade de vida, e altas taxas de emprego, não dependam do aumento dos níveis de consumo e dos produtos dos recursos naturais ou de atividades que diminuam a produtividade do ecossistema.

O estudo da economia em relação ao ambiente natural, hoje em dia, não é bem definido, mas sabe-se que sua principal característica é a necessidade de ser sustentável, considerando a capacidade de suporte dos ecossistemas. As energias devem ser conduzidas para a questão de como limitar a escala a um nível sustentável. Pode-se começar investigando os princípios operacionais da sustentabilidade e desenvolvendo-se ferramentas econômicas que evidenciem isso.

A questão ambiental tem sido tratada, dentro do pensamento econômico, no âmbito da microeconomia, buscando-se internalizar no preço de um produto os custos dos efeitos ambientais externos da produção, fazendo com que o preço final reflita a degradação do ambiente.

Essa internalização dos custos ambientais é um problema microeconômico e seria desejável que fosse largamente empregado, porém não é o que ocorre. A microeconomia se ocupa da análise custo/benefício de uma atividade localizada.

É constatado, de acordo com MERICO (1996), que não há dimensão macroeconômica da questão ambiental. Da mesma maneira que a microeconomia é parte de um sistema maior, no caso, a macroeconomia, esta também é parte de um sistema ainda maior: a biosfera.

A macroeconomia é um subsistema aberto da biosfera e é totalmente dependente dela, tanto como fonte de matéria/energia de baixa entropia como depósito de matéria/energia de alta entropia; 
desta forma, as trocas físicas que cruzam a fronteira entre o sistema ecológico total e o subsistema econômico constituem objeto de estudo da Economia Ecológica.

A economia necessita de uma escala adequada relativa ao ambiente natural, escala significando tamanho físico, volume físico do fluxo de matéria e energia de baixa entropia vindo dos ecossistemas e que retorna ao ambiente como alta entropia. A definição de uma escala da economia em relação ao ambiente natural é fundamental, pois a biosfera, da qual a economia é um subsistema, não cresce (FIGURA 1). Sendo a biosfera finita, é claro que o subsistema econômico não pode romper e degradar o ambiente natural indefinidamente. E sendo a biosfera a fonte de todos os materiais que alimentam a economia e o lugar de despejo de seus rejeitos, a economia tem que manter um tamanho que seus ecossistemas possam sustentar.

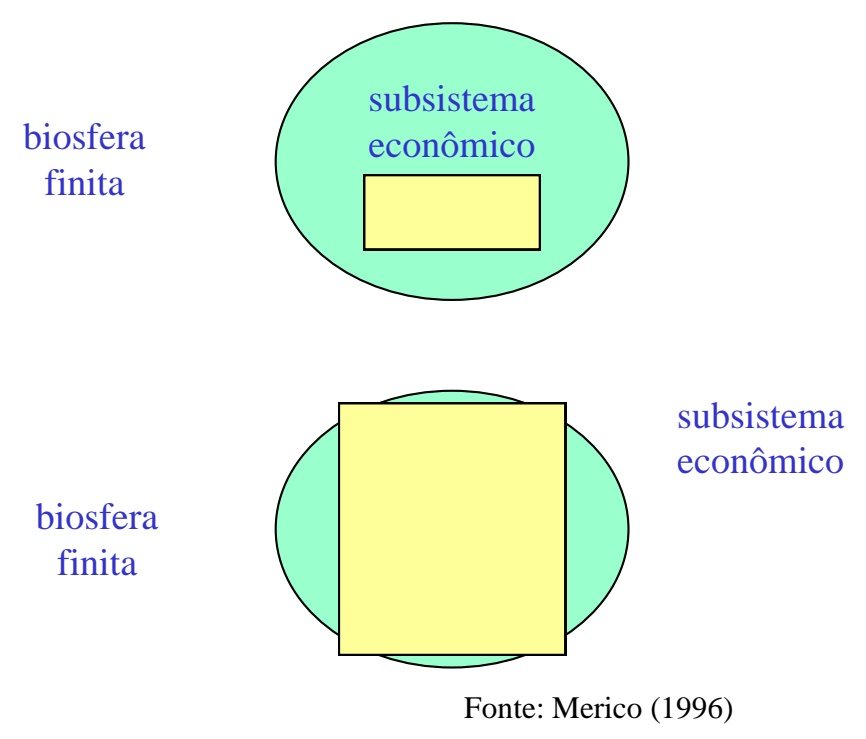

Figura 1 : Biosfera finita em relação ao crescente subsistema econômico

Caso o subsistema econômico ultrapasse a capacidade de sustentação dos ecossistemas, os processos de manutenção da vida no planeta podem se romper. Como não há a possibilidade de internalizar essa externalidade generalizada, representada pela destruição dos ecossistemas básicos do planeta, uma alternativa é a incorporação da destruição (externalidades) nos preços dos produtos e serviços.

O primeiro requisito de um modelo de processo econômico ecologicamente sustentável pede que se saiba de que forma o sistema econômico depende do ecossistema - seja na função deste último como fonte de recursos, seja como cesta de lixo, depósito ou fossa dos resíduos da dissipação de matéria e energia (CAVALCANTI, 1996).

A imposição de limites biofísicos sustentáveis é que determinará uma escala adequada para a economia e evitará o rompimento desses ecossistemas. A capacidade de sustentação dos ecossistemas será garantida quando forem seguidos os seguintes pressupostos: 
a) não retirar dos ecossistemas mais que sua capacidade de regeneração;

b) não lançar aos ecossistemas mais que sua capacidade de absorção (MERICO, 1996).

Um processo econômico é verdadeiramente sustentável quando três funções ambientais críticas não são desrespeitadas, de acordo com CAVALCANTI (1996):

1. de provisão de recursos;

2. de absorção e neutralização dos dejetos da atividade econômica;

3. de manutenção da oferta de serviços ambientais, desde as condições de amenidade propiciadas pelo "verde" a funções como a de estabilidade climática.

No momento em que o sistema econômico criado pelo ser humano deixa de ser compatível com o sistema ecológico que a natureza oferece, existe a necessidade de uma nova adaptação das relações entre o Homem e a Natureza. Surge desta maneira a proposta da avaliação econômica do meio ambiente, que não tem como objetivo dar um "preço" a um certo tipo de meio ambiente e sim mostrar o valor econômico que o meio ambiente pode oferecer e o prejuízo irrecuperável que pode haver caso seja destruído (FIGUEROA, 1996).

Importante ressaltar também, que segundo MERICO (1996), não há dinheiro ou tecnologia capaz de substituir os serviços ambientais proporcionados pela biodiversidade, regulação climática, ciclo hidrológico, proteção da camada de ozônio e por tantos outros.

Os custos da degradação ambiental e do consumo de recursos naturais não têm sido computados nos processos econômicos. Para que esse processo econômico continue a ser produtivo um preço terá que ser pago.

PEARCE \& TURNER (1991) acreditam que, se algo é proporcionado a preço zero, sua demanda será maior do que se tivesse um preço positivo. E a grande demanda pode ultrapassar a capacidade do ecossistema de sustentá-las.

Reconhecendo que a biodiversidade, os recursos naturais e serviços ambientais têm funções econômicas e valores econômicos positivos, e que tratando-os como preço zero é um risco muito grande de exauri-los, ou manejá-los insustentavelmente, tem-se a importância de valorar corretamente o ambiente natural e integrar esses valores corretos às políticas econômicas, assegurando, assim, uma melhor alocação de recursos.

Um princípio básico, segundo MARQUES \& COMUNE (1996), a ser observado é que o ambiente e o sistema econômico interagem, quer através dos impactos que o sistema econômico provoca no ambiente, quer através do impacto que os recursos naturais causam na economia.

Ter a idéia de quanto vale o ambiente natural e incluir esses valores na análise econômica é, pelo menos, uma tentativa de corrigir as tendências negativas do livre mercado.

As variações dos preços de certa forma atuarão no sentido de evitar o desperdício de recursos em via de esgotamento relativo, mas seria perigoso abandonar esses problemas à mercê do 
mercado, sendo que a regra da economia de mercado é deixar que as empresas internalizem os lucros e externalizem os custos à sociedade.

A eliminação dos desperdícios e a manutenção, em níveis toleráveis, quer pela produção, quer pelo consumo de determinados produtos, levantarão também o problema dos limites ao incremento dos consumos materiais, em benefício dos serviços sociais concebidos no sentido mais amplo do termo, levando a um perfil de desenvolvimento menos intensivo em recursos e menos degradante para o ambiente (SACHS, 1986).

Apesar da idéia de evidenciar os valores monetários do ambiente natural parecer, sob certos aspectos, imoral, ela se justifica pelo fato de que estes valores monetários podem ser utilizados como padrão de medida, indicando ganhos e perdas em utilidade e bem-estar.

A internalização dos custos ambientais do processo produtivo, para que cada atividade tenha seus impactos propriamente contabilizados, é uma excelente ferramenta para melhorar a alocação de recursos econômicos, mas é um processo que depende basicamente da identificação de impactos ambientais e de sua correta valoração econômica.

A valoração ambiental é essencial, caso se pretenda que a degradação da grande maioria dos recursos naturais seja interrompida antes que ultrapasse o limite da irreversibilidade.

\section{Valor econômico total}

A idéia de se evidenciarem os valores monetários dos recursos naturais se justifica pelo fato de que estes valores monetários podem ser utilizados como padrão de medida. O valor econômico do meio ambiente tem sido objeto de intensa discussão.

Para alcançar o desenvolvimento sustentável, pela linha da economia ecológica, torna-se necessário que os bens e serviços ambientais sejam incorporados à contabilidade econômica dos países.

Embora defenda a necessidade de se dar valores aos ecossistemas, a economia ecológica faz algumas críticas sobre os princípios em que se assenta a valoração econômica apoiada nos conceitos e hipóteses da teoria neoclássica. As críticas estão centradas no princípio da soberania do consumidor e na revelação das preferências para avaliar os bens e serviços ecológicos que produzem pouco ou nenhum impacto a longo prazo, mas inadequadas para se aplicar aos bens e serviços ecológicos que são de longo prazo. Outra crítica centra-se nos métodos desenvolvidos para valorar bens e serviços ambientais que não são transacionados no mercado, mas que procuram simular a existência de mercados para esses produtos.

A economia do meio ambiente, que se alicerça nos fundamentos da teoria neoclássica, desenvolveu e aprofundou não somente conceitos e métodos para a valoração do meio ambiente 
como também derivou importantes instrumentos de política, que vai do imposto "pigouviano" ao leilão de licenças para poluir, passando pelos subsídios, quotas, taxas, regulamentos e padrões fixados para o gerenciamento ambiental. Recentemente, tem-se a operacionalização dos conceitos de produção máxima sustentável e padrões mínimos de segurança, como meios de atingir determinada qualidade ambiental e sustentabilidade dos recursos naturais (MARQUES \& COMUNE, 1996).

Entre os diversos tipos de valor econômico relacionados aos recursos naturais, é necessário distinguir-se entre valor de uso e valor intrínseco. O valor de uso deriva do uso que se faz do ambiente, como a extração de recursos minerais ou a observação de pássaros. Já o valor intrínseco compreende os valores de algum bem, mesmo que potencial, tal como uma determinada espécie de planta ocorrente em área específica ou determinada espécie de inseto (MERICO, 1996).

O valor econômico total (VET) de um recurso consiste em seu valor de uso (VU) em seu valor de não-uso (VNU). O valor de uso pode ainda ser subdividido em valor de uso direto (VUD), valor de uso indireto (VUI) e valor de opção (VO) (valor de uso potencial). O valor de existência (VE) é uma das principais categorias do valor de não-uso.

Pode ser escrito:

$$
\begin{gathered}
\mathrm{VET}=\mathrm{VU}+\mathrm{VNU} \text { ou } \\
\mathrm{VET}=(\mathrm{VUD}+\mathrm{VUI}+\mathrm{VO})+\mathrm{VNU}
\end{gathered}
$$

Desta forma, o valor de uso direto é determinado pela contribuição direta que um recurso natural faz para o processo de produção e consumo. O valor de uso indireto inclui os benefícios derivados basicamente dos serviços que o ambiente proporciona para suportar o processo de produção e consumo. $\mathrm{O}$ valor de opção é a quantia que os consumidores estão dispostos a pagar por um recurso não utilizado na produção, simplesmente para evitar o risco de não tê-lo no futuro.

O valor de uso é atribuído pelas pessoas que realmente usam ou usufruem do meio ambiente em risco, por meio de dados estatísticos. Os valores de uso direto e indireto estão associados com as possibilidades presentes do uso dos recursos. Aquelas pessoas, porém que não usufruem do meio ambiente podem também valorá-lo em relação a usos futuros, seja para elas mesmas ou para gerações futuras. Esse valor é referido como valor de opção, ou seja, opção para uso futuro ao invés do uso presente conforme compreendido no valor de uso. O valor de existência é mais difícil de conceituar, já que representa um valor atribuído à existência do meio ambiente independentemente do uso atual e futuro.

Os valores de existência, de acordo com MARQUES \& COMUNE (1996), são aqueles expressos pelos indivíduos, de tal forma que não são relacionados ao uso presente ou futuro dos recursos ambientais pela geração presente e nem pelo possível uso que se possa atribuir em nome da 
geração futura. O conceito de valor de existência aproxima economistas e ecólogos, proporcionando um melhor entendimento da questão ambiental, na tentativa de captar todos os valores que um recurso ambiental possa conter.

As pessoas atribuem esses valores de acordo com a avaliação que fazem da singularidade e da irreversibilidade da destruição do meio ambiente, associadas à incerteza da extensão dos seus efeitos negativos. As categorias de valores de não uso são o valor de existência (VE) e o valor de legado (VL). Pode-se escrever:

$$
\mathrm{VET}=[\mathrm{VUD}+\mathrm{VUI}+\mathrm{VO}]+[\mathrm{VE}+\mathrm{VL}]
$$

O valor de opção é baseado em quanto os indivíduos estão dispostos a pagar pela opção de preservar um bem para uso pessoal direto ou indireto no futuro.

O valor de legado, excluindo valores próprios dos indivíduos, é o valor que as pessoas derivam do fato de que outras pessoas estarão aptas a beneficiar-se desse recurso no futuro. Ver

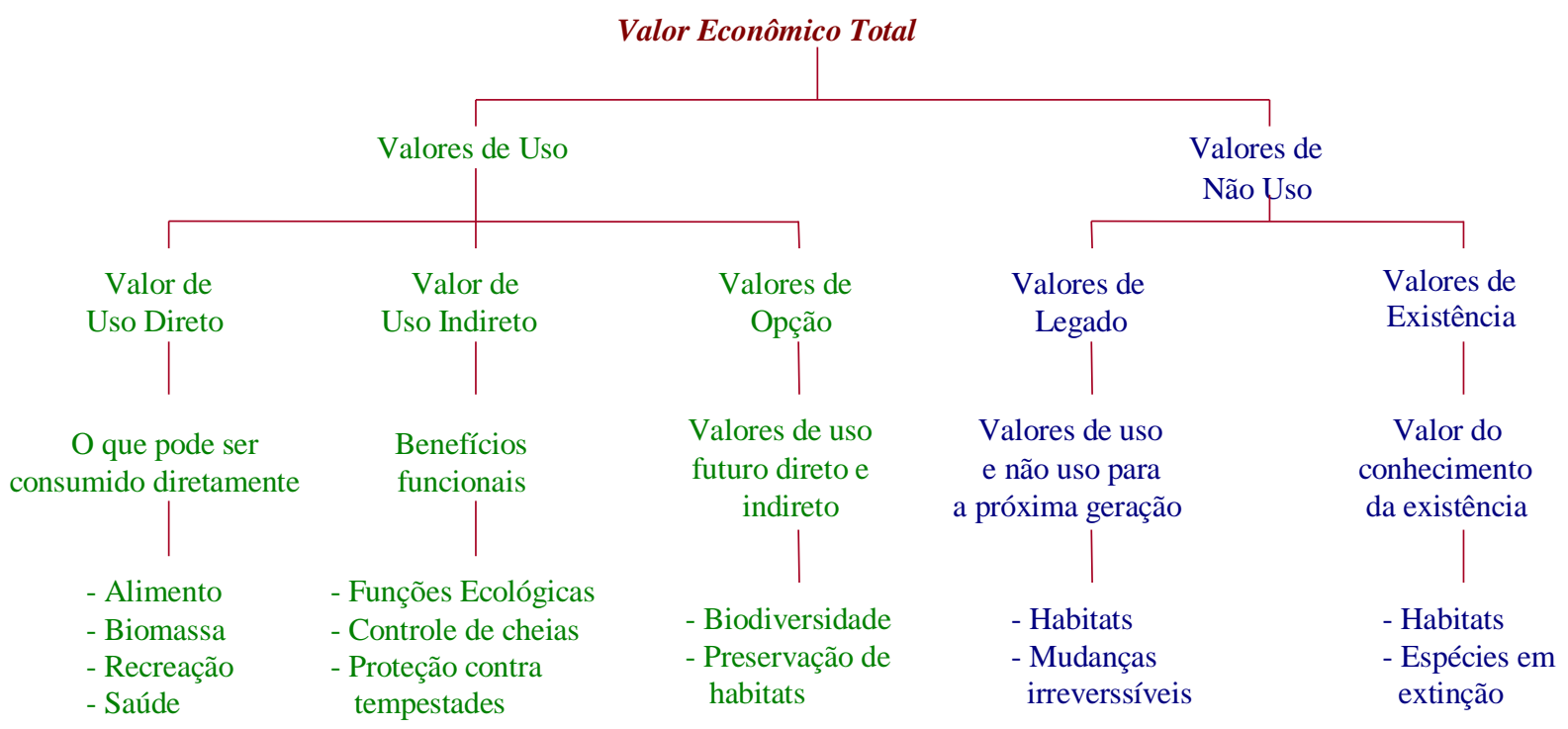

FIGURA (2).

Fonte: Figueroa (1996)

Figura 2 : Categorias de valores econômicos atribuídos ao patrimônio ambiental

\section{Métodos de valoração ambiental}

Os métodos de valoração, segundo MERICO (1996), de modo geral, não possuem uma classificação rígida, podendo-se utilizar diversos enfoques na aplicação dos métodos, dependendo dos propósitos. Do ponto de vista didático, no entanto, torna-se interessante uma abordagem maleável destes métodos que permita as alterações que se fizerem necessárias durante suas aplicações. 
Assim, duas categorias de métodos de valoração ambiental podem ser distinguidas da seguinte forma: métodos diretos e métodos indiretos.

\subsection{Métodos Diretos}

Os métodos diretos podem estar diretamente relacionados aos preços de mercado ou produtividade, e são baseados nas relações físicas que descrevem causa e efeito.

Representam métodos que encontram bastante utilização para a valoração do consumo de capital natural, principalmente quando se objetiva a contabilidade de estoques de recursos naturais e sua dedução da contabilidade de renda (nacional ou regional).

\subsection{Métodos Indiretos}

Os métodos indiretos são aplicados quando um impacto ambiental, um determinado elemento do ecossistema, ou mesmo todo um ecossistema não pode ser valorado, mesmo que indiretamente, pelo comportamento do mercado. Assim, estes métodos repousam sobre a utilização de um mercado de substituição definido pela análise dos comportamentos reais.

Procura-se com eles, evidenciar as preferências individuais, que estão relacionadas às funções de utilidade. Incluem-se, principalmente, os métodos de valoração contingente, custos de viagens e os valores hedônicos.

Em certos casos, quando mercados para bens e serviços ambientais não existem, ou não existem mercados alternativos para se proporem substituições, há a necessidade de se aplicarem métodos de valoração contingentes, ou seja, com certo grau de incerteza. Pode-se aplicar estes métodos para elementos da natureza, tal como a biodiversidade, patrimônio paisagístico, áreas de proteção ambiental, áreas de lazer, ou qualquer outra situação na qual não existam valores de mercado. A alternativa mais usada nestes casos é o método de disposição a pagar.

\section{Conclusão}

A teoria neoclássica de alocação pressupõe que o capital natural pode ser substituído infinitamente pelo capital material. Alguns autores como SIMON (1995) acreditam que o progresso tecnológico irá superar quaisquer limites que possam surgir ao crescimento devido à escassez dos recursos. Devido à ausência de instituições democráticas em pleno funcionamento ou da soberania do consumidor nos atuais mercados oligopólicos interdependentes, as decisões em relação aos trade-offs entre desenvolvimento e meio ambiente podem ser mal interpretadas pelos preceitos 
neoclássicos. Segundo ROMEIRO (1991), do ponto de vista tecnológico já existe uma série de alternativas, mas estas dependem da superação de interesses privados através da internalização dos custos ecológicos, que só serão aplicados através de uma sociedade consciente e organizada.

Agrediu-se a capacidade de suporte do ecossistema planetário sem adequada compensação para a população total do globo terrestre, ocasionando uma má distribuição de renda e, conseqüentemente, o aumento da miséria. Os problemas da pobreza e do meio ambiente, de acordo com SACHS (1993), podem ser sanados ou evitados, visto que não há quaisquer limites ecológicos ou falta de tecnologia que impeçam sua superação, concluindo-se que seus obstáculos são de origem social e política. É preciso, portanto, repensar o desenvolvimento econômico buscando formas de se obter um desenvolvimento que seja realmente sustentável. Segundo CAVALCANTI (1996), o desenvolvimento não pode mais ser tratado como sinônimo de crescimento, já que a natureza se desenvolve, os ecossistemas evoluem e atingem suas fases de clímax.

Para que uma sociedade seja sustentável, é necessário haver a integração do desenvolvimento com a conservação ambiental. A política econômica pode ser um eficaz instrumento para a sustentação dos ecossistemas e dos recursos naturais. Na falta de incentivos econômicos adequados, as políticas e as legislações que visam a proteção do meio ambiente e a conservação de recursos serão desconsideradas. Os sistemas convencionais costumam lidar com o meio ambiente e suas funções como sendo ilimitados ou gratuitos, desta forma, incentivam a exaustão dos recursos e a degradação dos ecossistemas. Todas as economias dependem do meio ambiente como fonte de serviços de sustentação da vida e de matérias-primas, portanto, os mercados e as economias planejadas deverão se conscientizar do valor desses bens e serviços, ou dos custos que a sociedade terá, caso os recursos ambientais sejam reduzidos ou os serviços, prejudicados.

Para haver um desenvolvimento sustentável é preciso que do ponto de vista econômico, o crescimento seja definido de acordo com a capacidade de suporte dos ecossistemas. Contemplando objetivos ecológicos relacionados com a integridade dos ecossistemas, com a preservação da biodiversidade, com respeito aos limites do meio ambiente físico. Paralelamente, no plano social, o modelo de desenvolvimento sustentável deve preocupar-se em promover a coesão e a mobilidade social, deve visar elevar a participação política dos cidadãos e respeitar sua identidade cultural, assegurando-lhes o acesso ao poder e o desenvolvimento das instituições sociais. Para que isso ocorra necessita-se uma revisão de grandes proporções em práticas e concepções vigentes, integrando-se valores econômicos e ambientais. 


\section{ABSTRACT}

Economical and social development and the environmental administration are inextricably linked and they should be treated by the change content, modalities and uses of the growth. Concern about environmental problems turns up as an important element regarding material and economical growth and life quality. The environment is considered a dimension of the development and then it should be internalizado in all the levels of decision. The neoclassical economical analysis, model dominant regarding the questions microeconomicals, it makes an effort to entrust to the market the resolution of the environmental problems. One largest limitations theory is that the economical systems give value to the goods and services produced by the Man and they don't value the goods and services produced by the Nature. Like this, the values data to the products and services don't correspond to your real values. As the operacionalization of the sustainabilite - understood as the capacity of the present generations they reach your needs without also committing the capacity of the future generations to do it - it's the great challenge of next decades, it's done necessary to look for instruments of the environmental administration that really guarantee a development sustainable.

Key words: Sustainable Development, Economical Valuation, Environment.

\section{Referências}

BUARQUE, C. O pensamento em um mundo terceiro mundo. In: BURSZTYN, M. et al. Para pensar o desenvolvimento sustentável. São Paulo: Brasiliense, 1994. p. 57-80.

CAVALCANTI, C. Condicionantes biofísicos da economia e suas implicações quanto à noção do desenvolvimento sustentável. In: ROMEIRO, A. R. et al. Economia do meio ambiente: teoria, políticas e a gestão de espaços regionais. Campinas : UNICAMP, 1996.

COMMON, M. Sustainability and Policy: limits to economics. Cambridge University Press, 1995.

CONSTANZA, R. Economia Ecológica: uma agenda de pesquisa. In: MAY, P. H.; MOTTA, R. S. Valorando a Natureza: análise econômica para o desenvolvimento sustentável. Rio de Janeiro: Campus, 1994. cap. 7. p.111- 144.

FIGUEROA, F. E. V. Avaliação econômica de ambientes naturais - o caso das áreas alagadas - uma proposta para a represa do lobo (Broa) - Itirapina - SP. São Carlos. Dissertação (Mestrado em Ciências da Engenharia Ambiental) Escola de Engenharia de São Carlos, Universidade de São Paulo. 1996.

MARQUES, J. F.; COMUNE, A .E. A teoria neoclássica e a valoração ambiental. In: ROMEIRO, A. R. et al. Economia do meio ambiente: teoria, políticas e a gestão de espaços regionais. Campinas: UNICAMP, 1996.

MAY, P. Economia ecológica e o desenvolvimento eqüitativo no Brasil. In: CAVALCANTI, C. Desenvolvimento e natureza: estudo para uma sociedade sustentável. São Paulo: Cortez; Recife: Fundação Joaquim Nabuco, 1995. cap. 13. p. 235-255.

MAY, P. H. Avaliação integrada da economia do meio ambiente: propostas conceituais e metodológicas. In: ROMEIRO, A. R. et al. Economia do meio ambiente: teoria, políticas e a gestão de espaços regionais. Campinas: UNICAMP, 1996.

MERICO, L. F. K. Introdução à economia ecológica. Blumenau : FURB, 1996.

PEARCE, D. W.; TURNER, R. K. Economics of natural resources and the environmental. Baltimore, Maryland: The Johns Hopkins University Press, 1991.

ROMEIRO, A. R. Desenvolvimento econômico e a questão ambiental: algumas considerações. Revista Análise Econômica da UFRGS, v. 9, n. 16, set. 1991.

SACHS, I. Ecodesenvolvimento: crescer sem destruir. São Paulo: Vértice, 1986.

SACHS, I. Estratégias de transição para o século XXI: desenvolvimento e meio ambiente. São Paulo: Studio Nobel; Fundação do Desenvolvimento Administrativo, 1993.

SIMON, J. The state of humanity. Oxford/UK and Cambridge/USA : Blackwell, 1995.

TOLMASQUIM, M. T. Economia do meio ambiente: forças e fraquezas. In: CAVALCANTI, C. Desenvolvimento e natureza: estudo para uma sociedade sustentável. São Paulo: Cortez; Recife: Fundação Joaquim Nabuco, 1995. cap. 17. p. 323-341. 